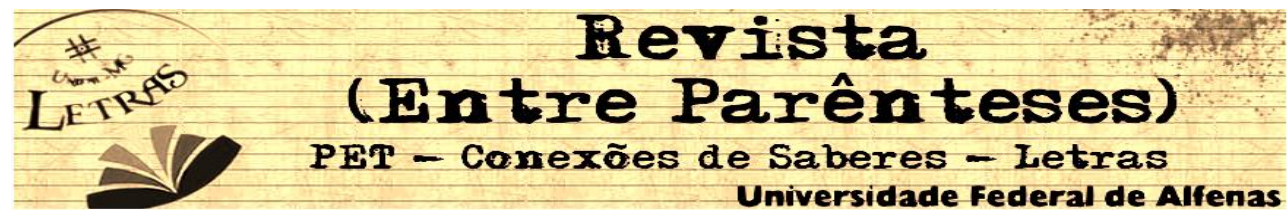

\title{
A Influência do Futebol no Léxico do Português Brasileiro
}

\author{
Helieucio de Oliveira ${ }^{1}$ \\ Universidade Federal de Alfenas \\ helieucio@outlook.com \\ Celso Ferrarezi Junior² \\ Universidade Federal de Alfenas \\ cferrarezij@superig.com.br
}

Resumo: Muitas expressões que usamos em nosso vocabulário tiveram origem no futebol como, por exemplo, "dar bola fora", "deixar pra escanteio" e "pisar na bola". Essas são expressões comuns que falamos a todo o tempo, que foram absorvidas pela língua e são comumente usadas, inclusive por aqueles que não se identificam com esse esporte. Tendo isso em mente, esta pesquisa visa a analisar a influência do futebol no português brasileiro, as formas como esse esporte contribui para a formação de nossa linguagem cotidiana e os elementos que, a partir dele, são incorporados em nosso dia-a-dia.

Palavras-chave: 1. Léxico. 2. Futebol. 3. Expressões idiomáticas. 4. Português brasileiro.

Abstract: A lot of expressions that we use in our vocabulary had origin in soccer, such as, "dar bola fora", "deixar para escanteio" and "pisar na bola". These are common expressions we talk all the time, which were absorbed by the language and are commonly used, even by those who do not identify with this sport. With that in mind, this research aims to analyze the influence of soccer in the Brazilian Portuguese, the ways that this sport contributes to the formation of our everyday language and the elements that, from it, are embedded in our day to day.

Key words: 1. Lexicon. 2.; Soccer. 3. Idiomatic expressions. 4. Braziliam Portuguese.

\footnotetext{
${ }^{1}$ Pesquisador voluntário do Grupo de Pesquisas Linguísticas Descritivas, Teóricas e Aplicadas

${ }^{2}$ Professor Dr. Celso Ferrarezi Junior, Grupo de Pesquisas Linguísticas, Teóricas e Aplicadas

Revista (Entre Parênteses) - ISSN 2238-4502 


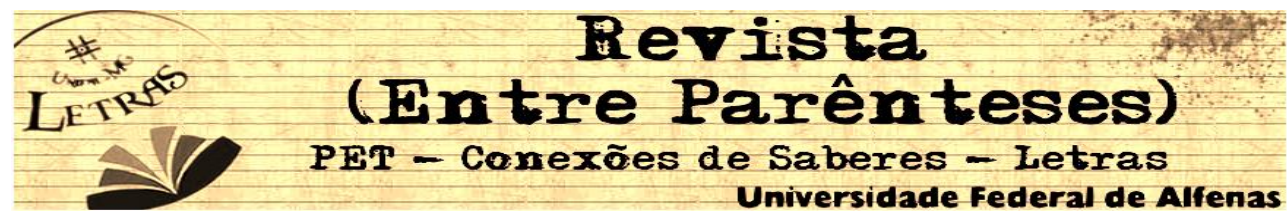

\section{Introdução}

Introduzido no Brasil por Charles Miller no final do século XIX, o futebol é um dos maiores representantes da cultura nacional. Ele está presente a todo o momento no radio, na $\mathrm{TV}$, na Internet, nos jornais e, evidentemente, nas conversas do dia-a-dia. O futebol movimenta o equivalente a $\mathrm{R} \$ 16$ bilhões por ano e possui mais de trinta milhões de praticantes no país, o que faz com que deixe profundas marcas em nossa cultura e, consequentemente, em nossa língua. Por ser tão importante e significativo, as expressões vindas do futebol estão sempre presentes no nosso vocabulário e são utilizadas corriqueiramente pelos falantes do português. Além disso, é preciso ter em vista que, apesar ser tão importante, culturalmente falando, para o brasileiro, o futebol e sua linguagem, assim como seu processo de transposição para o léxico, foi pouquíssimo estudado.

O estudo das expressões idiomáticas é uma das maneiras mais eficazes de compreender a influência do futebol no léxico do português brasileiro. Construções como dar bola fora ou deixar pra escanteio são muito comuns em nosso dia-a-dia e são perfeitamente compreendidas pelos falantes, independentemente do contexto em que elas sejam utilizadas. Fazer um levantamento acerca desses termos e analisar seu uso em diferentes contextos e cenários nos ajudará a ter uma noção aproximada do tamanho da influência do futebol em nossa língua. Assim, justifica-se a necessidade de fazer estudo aprofundado das expressões idiomáticas para que se possa obter dados importantes a respeito das marcas deixadas pelo futebol no léxico, assim como ter uma noção a respeito da produtividade linguística dessas expressões.

Portanto, esta pesquisa tem como objetivo analisar a influência do futebol no português brasileiro visando a descobrir quais as expressões que ocorrem com maior frequência e, também, analisar a o quanto essa expressão é produtiva na língua, tendo em vista que muitas dessas expressões idiomáticas são utilizadas em variados contextos e com significados completamente distintos.

Para analisar essas expressões e, consequente, entender seus diferentes usos e significados usaremos os conceitos propostos por Ferrarezi Jr. (2010) em "Introdução à Semântica de Contextos e Cenários: de la langue à la vie”. A Semântica de Contextos e Revista (Entre Parênteses) - ISSN 2238-4502 


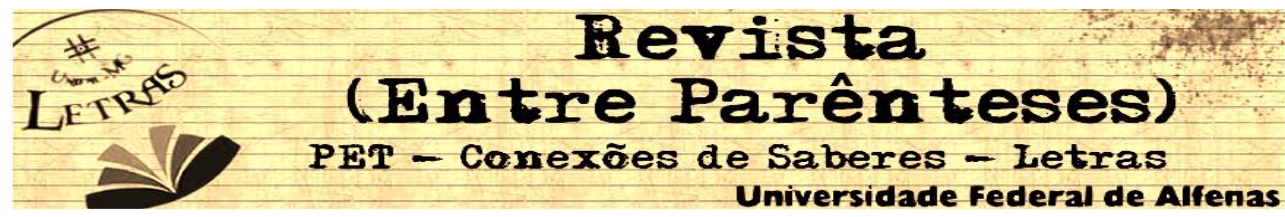

Cenários nos ajudará a compreender como a construção de uma linguagem própria do futebol foi transposta para o cotidiano dos brasileiros e ganhou significações diversas, a ponto de a mesma expressão assumir em inúmeros casos valores de sentido diferentes, variando de acordo com o contexto e, também, de acordo com o cenário em que esta inserida.

\section{Referencial Teórico:}

O futebol constitui-se uma das mais importantes expressões culturais do Brasil e sua influência pode ser notada de várias maneiras. Ainda que, por muitas vezes, não percebamos, o futebol se mostra presente em nosso cotidiano por meio de expressões que foram incorporadas ao nosso léxico. Em inúmeras ocasiões, nos valemos de expressões idiomáticas que tiveram origem a partir dele para nos comunicar de maneira mais eficaz.

Embora essa influência seja facilmente constatada em nosso falar cotidiano, através de expressões como entrar de sola, estar na marca do pênalti e pendurar as chuteiras, muito pouco se estudou sobre esse fenômeno e o que ele representa para o falante do português brasileiro. Portanto, como dito anteriormente, ao discutir sobre essa influência a partir de análises das expressões idiomáticas, poderemos entender como determinados termos do futebol foram transpostos para o nosso léxico e são usados de maneira corriqueira pelos falantes do português. Os estudos das expressões idiomáticas possibilitam também que tenhamos uma noção muito precisa a respeito da produtividade da linguagem própria do futebol em nossa língua, tendo em vista que muitas dessas expressões assumem valores semânticos diferentes do contexto que as originou, assumindo significações diversas de acordo com a situação. Segundo Riva:

Embora as línguas disponham de meios para expressar objetivamente os acontecimentos, os sentimentos, as ideias, as EIs originam-se da vontade do usuário de comunicar experiências de maneira mais expressiva ou pitoresca, de ser mais persuasivo, de despertar o cômico ou o irônico, por meio de combinatórias inusitadas que são unidades funcionais significativas do discurso, constituídas por sequências estereotipadas de lexemas.(RIVA, 2009, p.23) 


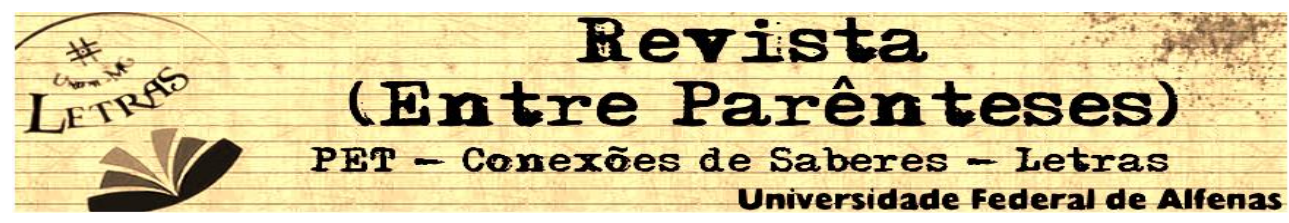

As expressões idiomáticas são grupos de palavras que foram cristalizadas na língua e atuam de maneira conjunta, fora de seu significado usual, não podendo ser definidas de maneira literal, conforme explica (BIDERMAN apud RIVA, 2009) “os idiomatismos são combinatórias de lexemas que o uso consagrou numa determinada sequência, ou seja, desconsiderando suas partes como unidades semânticas e cujo significado não se dá na simples somatória dessas partes".

Sendo o futebol uma parte importante da cultura brasileira, podemos afirmar que o fato dos falantes do português brasileiro adotarem expressões advindas dele para expressarem-se em situações diversas nos evidencia que a língua está diretamente relacionada à cultura e a visão de mundo dos falantes, essa relação entre língua e cultura é destacada por FERRAREZI (2010) ao enfatizar que:

[...] os sentidos se constroem culturalmente, e tudo o que é construído culturalmente é, obrigatoriamente, vinculado a valores culturais. Por isso mesmo, os sentidos expressam, além de suas associações referenciais, valores culturais e, assim, geram a impressão desses valores nas mentes dos falantes. (Ferrarezi Jr, p.123)

Assim, um falante do português, ao usar a expressão "pisar na bola" para afirmar que outra pessoa cometeu um deslize, estará manifestando-se por meio de uma metáfora relacionada ao futebol, isso não obriga seu interlocutor a ter noções básicas sobre futebol. Logo, para haver comunicação entre os interlocutores, não há necessidade de os falantes conhecerem as regras e as peculiaridades desse esporte. Essa situação ocorre porque os sentidos das palavras são culturalmente determinados, e ao fazer parte de nossa cultura, o futebol acaba por se materializar no léxico. 


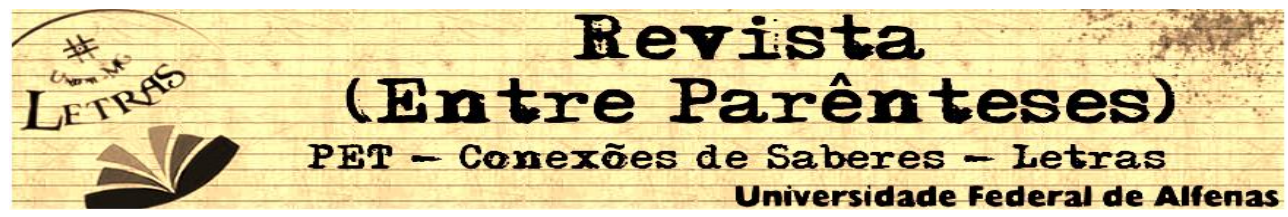

\section{A pesquisa}

Para realizar esta pesquisa utilizou-se o Google como ferramenta para coleta de dados. As expressões utilizadas para a coleta foram selecionadas a partir do "Dicionário Futebolês Português", de Luiz Saraiva Feijó. Inicialmente verificou-se o número de ocorrências de determinadas expressões assim como seus respectivos usos em vários contextos distintos, sendo que, nenhum deles relacionado ao futebol.

Ao buscar, por exemplo, a expressão deixar pra escanteio, no site de pesquisas citado, encontramos mais de 486.000 resultados. Utilizando o mesmo procedimento de busca com a expressão dar bola fora, o resultado é ainda mais significativo, com aproximadamente 1.750.000 ocorrências do termo. Já a expressão entrar de sola, se mostra ainda mais produtiva e utilizada que as duas anteriores, com aproximadamente 36.900 .000 de resultados na busca.

É importante ressaltar que, ao analisar a ocorrência dessas expressões na Internet, nota-se que seu uso nem sempre está relacionado ao futebol. Com a pesquisa pode-se constatar que muitas expressões idiomáticas, embora tenham tido sua origem a partir futebol, encontram maior uso fora da esfera esportiva, nas conversas do cotidiano. $\mathrm{O}$ fato de grande parte de esse uso acontecer fora do futebol, explica o número tão significativo de ocorrências e mostra como essas expressões estão cristalizadas no léxico.

Para que tenhamos uma noção da produtividade dessas expressões no português brasileiro, alguns exemplos que serão analisados mostram a mesma expressão sendo utilizada de maneiras distintas e em contextos completamente diferentes. Com a expressão no banco de reservas, por exemplo, ocorrem cerca de 34.500 .000 de resultados na pesquisa em ambiente virtual e podem ser verificadas, inclusive, variações de sentido, como os que serão apresentados a seguir: 


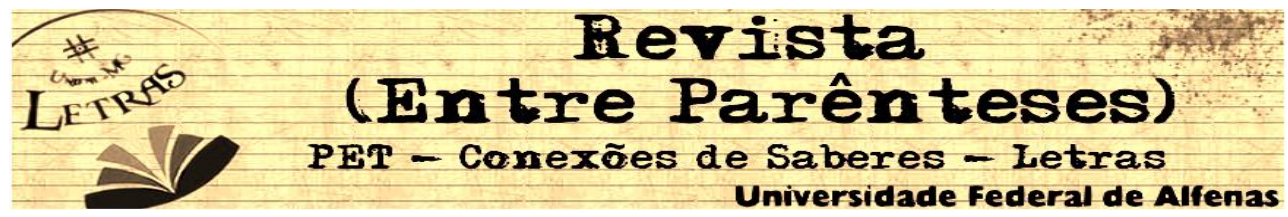

a. "Não aceite ser tratada com indiferença e não assuma um espaço cativo no banco de reservas." 3

No futebol, banco de reservas é o local onde ficam os jogadores que estão aptos a entrar no decorrer de uma partida e, também, os demais membros da comissão técnica. Porém, neste exemplo, podemos notar que a expressão banco de reservas está completamente fora de seu sentido original. O falante, neste caso, a está utilizando como metáfora para expressar a ideia de que a pessoa deve se precaver para que não seja deixada em segundo plano em uma relação. Entretanto, fora da linguagem do futebol seu uso não se resume a apenas uma situação especifica, quando empregadas fora de seu campo origem, as expressões idiomáticas podem assumir um ou até mesmo vários sentidos diferentes, variando de acordo com o contexto e o cenário em que está inserida. Podemos ver, neste outro exemplo, a mesma expressão com um sentido diferente do exemplo anterior.

\section{b. "Se o Lula sair do banco de reservas, a disputa se embolará de vez."4}

Neste contexto banco de reservas remete à não participação efetiva do ex-presidente na campanha eleitoral, ou seja, se o Lula participar de maneira mais efetiva, a disputa se embolará de vez. Podemos notar que, embora não haja alteração nenhuma na estrutura, a expressão possui valores semânticos diferentes, remetendo a duas coisas completamente distintas.

Esse tipo de variação de sentido é muito comum em língua naturais e naõ poderia ser diferente no português brasileiro, e pode ser notada também em outros exemplos:

c. "Atriz mostra que aos 48 anos está batendo um bolão.",

\footnotetext{
${ }^{3}$ Disponível em: https://mulherao.wordpress.com/2010/09/06/voce-e-a-prioridade-ou-uma-opcao-paraquem-diz-te-amar/ 6 de novembro de 2014.

${ }^{4}$ Disponível em: http://naufrago-da-utopia.blogspot.com.br/2014/08/se-o-lula-sair-do-banco-dereservas.html/ Acesso em: 6 de novembro de 2014.

${ }^{5}$ Disponível em:

http://www.paranaonline.com.br/editoria/almanaque/news/687941/?noticia=ATRIZ+MOSTRA+QUE+AOS+48+ ANOS+ESTA+BATENDO+UM+BOLAO Acesso em: 6 de novembro de 2014
} 


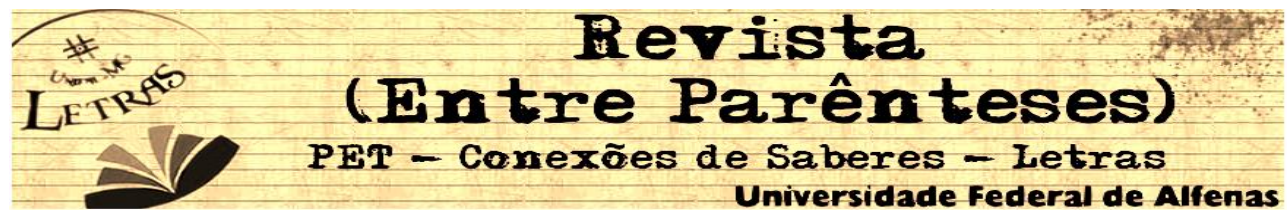

No futebol é comum dizer que determinada equipe ou atleta está batendo um bolão, e significa que ela ou ele está tendo um desempenho acima da média, superando as expectativas. Mas, como podemos notar na frase acima, a expressão batendo um bolão ganha um sentido muito diferente do costumeiro em que ela é empregada na linguagem esportiva. Aqui, batendo um bolão está definindo que a atriz em questão possui um corpo bonito, que ainda é "gostosa", para usar outra expressão da linguagem popular. Porém, essa não é a única forma em que a expressão é empregada no dia-a-dia. Em um contexto diferente podemos encontrá-la com outro significado além dos dois já citados.

\section{d. "Fernanda Gentil bate um bolão na TV."}

Apesar de a expressão ainda estar fazendo referência a alguém do sexo feminino, diferentemente da construção anterior, neste contexto, a expressão se refere ao desempenho profissional: Fernanda Gentil tem desempenhado bem sua função TV. Neste exemplo, esta expressão possui um valor de sentido mais próximo daquele que é corriqueiramente usado no futebol. Embora sejam áreas completamente distintas, em ambos os casos ela se refere ao desempenho profissional.

Há, também, casos de expressões que pouco, ou até mesmo nada, variam em relação ao sentido. Isto, porém, não faz com que seu uso fique restrito somente à esfera esportiva ou, então, ser menos aproveitada em diferentes situações do dia-a-dia. A produtividade da expressão é ampla, mesmo que seu sentido não varie quando utilizada fora do futebol, e seu uso pode ser verificado em vários contextos diferentes, como veremos nestes três exemplos a seguir:

e. "Vestir a camisa do governo é engajar-se na busca dos resultados que a prefeitura necessita para o bem do município e de seu povo. "7

f. "No mundo fascinado por trabalho em que vivemos, é recorrente a ideia de que bons profissionais são aqueles que vestem a camisa da empresa. ",

\footnotetext{
${ }^{6}$ Disponível em: http://diariogaucho.clicrbs.com.br/rs/entretenimento/ola/noticia/2014/06/coluna-da-flaviafernanda-gentil-bate-um-bolao-na-teve-4537907.htm Acesso em: 6 de novembro de 2014

${ }^{7}$ Disponível em: http://www.jornaldebelmonte.com.br/vestir-a-camisa-do-governo-para-vencer-os-desafios/ Acesso em: 14 de março de 2015 


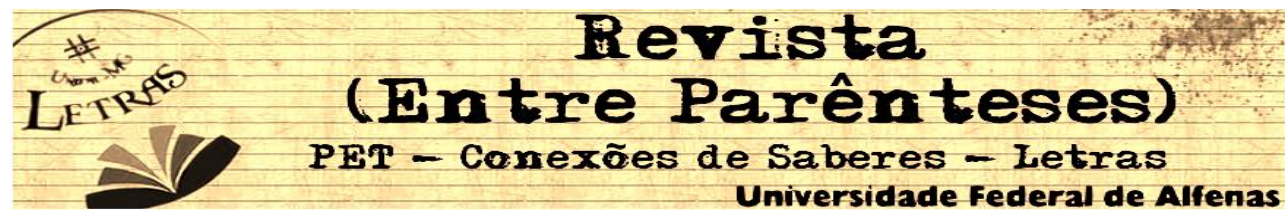

g. "Com esta reflexão, chamamos vocês a vestirem a camisa do relacionamento, do casamento e a lutarem por ele." 9

Nestes três exemplos, a expressão vestir a camisa remete a se engajar, entregar-se a alguma causa, portanto, tem um sentido muito próximo daquele que é costumeiramente usado no futebol. Apesar de não ocorrer nenhuma variação semântica grave, a expressão ainda se mostra extremamente produtiva, e pode ser utilizada em muitas situações diferentes. O mesmo acontece com a expressão na marca do pênalti: seu sentido muitas vezes não varia quando utilizada fora do universo do futebol, mas ela ainda se mostra produtiva, com seu uso sendo empregado em situações distintas sem que haja problema na comunicação. São exemplos disso:

\section{h. "Temperatura Máxima da Globo está na marca do pênalti.",10}

\section{i. "Crise na campanha de Richa põe secretários na marca do pênalti",11}

No futebol, o pênalti é um tiro livre direto sem barreira com a bola posicionada a onze metros do gol, logo, a bola estar na marca do pênalti significa que o gol, momento principal da partida, pode estar próximo de ser marcado. Nos dois exemplos mostrados, na marca do pênalti trazem sentidos muito parecidos, que é algo importante que está na iminência de acontecer, no caso, tanto o programa de TV quanto os secretários de campanha de um candidato estão prestes a serem retirados, ou do ar, ou da campanha. Em ambos os casos, o falante do português consegue inferir significado e entender perfeitamente o enunciado.

\footnotetext{
${ }^{8}$ Disponível em: http://exame.abril.com.br/carreira/noticias/o-lado-ruim-de-vestir-a-camisa-da-empresa Acesso em: 14 de março de 2015

${ }^{9}$ Disponível em: http://dinamicasdiversas.blogspot.com.br/2012/04/dinamica-do-barquinho-de-papelcasais.html Acesso em: 14 de março de 2014

${ }^{10}$ Disponível em: http://televisao.uol.com.br/colunas/flavio-ricco/2014/05/31/temperatura-maxima-da-globoesta-na-marca-do-penalti.htm Acesso em: 6 de novembro de 2014

${ }^{11}$ Disponível em: http://www.esmaelmorais.com.br/2014/08/datafolha-crise-na-campanha-de-richa-e-poesecretarios-na-marca-do-penalti/ Acesso em: 6 de novembro de 2014 


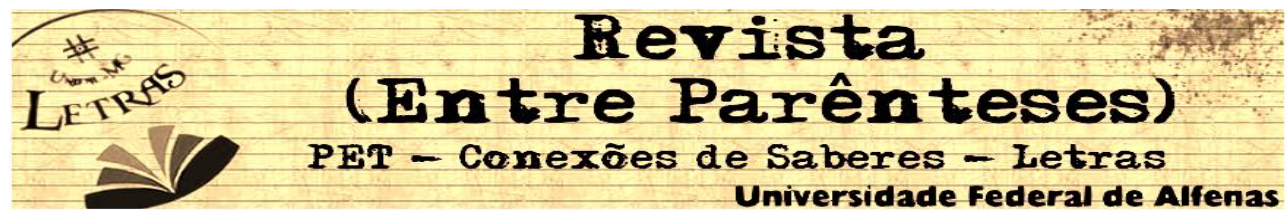

\section{Considerações finais}

Desta forma, é possível concluir que várias metáforas típicas do futebol foram transpostas para o léxico do português sem perder seu sentido original, e, em outros casos, elas variam de sentido de acordo com o contexto e o cenário. Entretanto isso não limitou de maneira alguma seu uso, e são utilizadas constantemente pelos falantes da língua em todas as esferas sociais, o que nos dá uma noção do tamanho da abrangência desse esporte e como ele se faz presente no cotidiano do brasileiro.

As expressões idiomáticas oriundas do futebol se fazem presentes em textos de jornais, revistas, blogs dos mais variados temas e graus de formalidade. Isso demonstra a influência do futebol em nosso léxico e, ainda, que seu uso não está restrito as falas e textos mais informais, tendo em vista que suas expressões são encontradas inclusive em textos jornalísticos de veículos de mídia de grande circulação e em assuntos que nada remetem ao futebol.

O falante do português não sente dificuldade em atribuir sentido a essas expressões e isso ocorre por que a língua é diretamente influenciada pela cultura do falante e os sentidos são construídos a partir dos conhecimentos compartilhados pela sociedade. Portanto, o futebol como parte importante dessa cultura, se transforma em elemento comum no léxico a ponto de que os falantes, mesmo os que não compartilham conhecimentos específicos sobre o esporte, tenham a capacidade de atribuir sentido e valores semânticos diferentes a essas expressões e utilizá-las no seu dia-a-dia.

\section{Referências:}

- FEIJÓ, Luiz César Saraiva. Dicionário Futebolês - Português. Rio de Janeiro: Francisco Alves Editora, 2006.

- GEERTZ, Clifford. A interpretação das culturas. $1^{\text {a }}$ Ed. (Reimpr.). Rio de Janeiro: LTC, 1926-2011. 


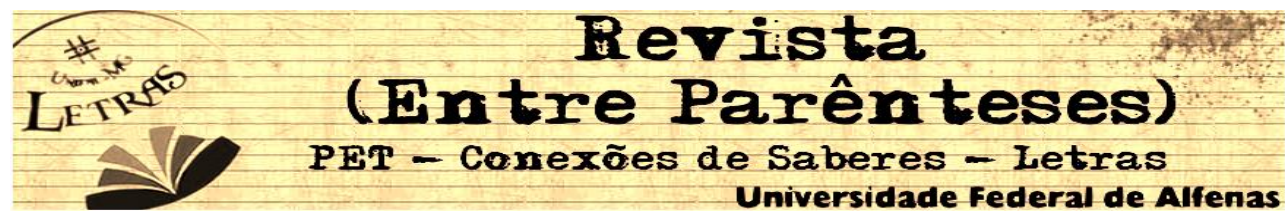

- FERRAREZI Jr., Celso. Introdução à Semântica de Contextos e Cenários: de la langue à la vie. Campinas, SP: Mercado de Letras, 2010.

- RODRIGUES, Gislaine. A linguagem do futebol no ensino do português. São José do Rio Preto

- RIVA, Huélinton Cassiano. Dicionário Onomasiológico das Expressões Idiomáticas Usuais na Língua Portuguesa do Brasil, São José do Rio Preto, 2009 